\title{
Ni@Pd core-shell nanoparticles supported on a metal-organic framework as highly efficient catalysts for nitroarenes reduction
}

\author{
Siping Jian, Yingwei Li ${ }^{*}$ \\ State Key Laboratory of Pulp and Paper Engineering, School of Chemistry and Chemical Engineering, South China University of Technology, Guanzhou \\ 510640, Guangdong, China
}

\section{A R T I C L E I N F O}

\section{Article history:}

Received 7 June 2015

Accepted 19 June 2015

Published 5 January 2016

\section{Keywords:}

Nickel

Palladium

Core-shell nanoparticle

Metal-organic framework

Nitroarene

Hydrogenation

Heterogeneous catalysis

\begin{abstract}
A B S T R A C T
Ni@Pd core-shell nanoparticles with a mean particle size of 8-9 nm were prepared by solvothermal reduction of bivalent nickel and palladium in oleylamine and trioctylphosphine. Subsequently, the first-ever deposition of Ni@Pd core-shell nanoparticles having different compositions on a metal-organic framework (MIL-101) was accomplished by wet impregnation in $n$-hexane. The Ni@Pd/MIL-101 materials were characterized by powder X-ray diffraction, Fourier transform infrared spectroscopy, transmission electron microscopy, and energy-dispersive X-ray spectroscopy and also investigated as catalysts for the hydrogenation of nitrobenzene under mild reaction conditions. At $30^{\circ} \mathrm{C}$ and $0.1 \mathrm{MPa}$ of $\mathrm{H}_{2}$ pressure, the Ni@Pd/MIL-101 gives a TOF as high as $375 \mathrm{~h}^{-1}$ for the hydrogenation of nitrobenzene and is applicable to a wide range of substituted nitroarenes. The exceptional performance of this catalyst is believed to result from the significant Ni-Pd interaction in the core-shell structure, together with promotion of the conversions of aromatics by uncoordinated Lewis acidic $\mathrm{Cr}$ sites on the MIL-101 support.
\end{abstract}

(C) 2016, Dalian Institute of Chemical Physics, Chinese Academy of Sciences. Published by Elsevier B.V. All rights reserved.

\section{Introduction}

Palladium (Pd) is well-known as an important noble metal catalyst and is widely used in hydrogenation, oxidation, coupling, and other reactions [1-4]. Heterogeneous catalysis by Pd is typically based on supported Pd nanoparticles (NPs). However, the catalytic reactions associated with these materials occur solely on the NP surfaces, such that the majority of the metal atoms, in the NP cores, are wasted [5]. It is therefore beneficial to expose as many $\mathrm{Pd}$ atoms as possible so as to achieve high specific activity and reduce the usage of this precious metal. In recent years, core-shell NPs have attracted intense interest as a result of their superior performance com- pared with monometallic noble metal NPs, an effect that arises due to core-shell interactions [6-10]. Although core-shell bimetallic NPs synthesized with two noble metals show excellent catalytic activity, the synthesis of such NPs by combining an inexpensive metal core with a noble metal shell is more attractive [11].

$\mathrm{Ni@Pd} \mathrm{bimetallic} \mathrm{NPs} \mathrm{have} \mathrm{been} \mathrm{studied} \mathrm{intensely} \mathrm{because}$ both Ni and Pd are group VIII metals and thus have similar peripheral electron configurations. Moreover, they both are active in the hydrogenation of unsaturated compounds [12,13]. Hyeon and co-workers [11] successfully synthesized $\mathrm{Ni@Pd}$ core-shell NPs through thermal decomposition of palladium and nickel precursors, although the recovery of these NPs from

\footnotetext{
*Corresponding author. Tel: +86-20-87113656; E-mail: liyw@scut.edu.cn

This work was supported by the National Natural Science Foundation of China (21322606 and 21436005), the Specialized Research Fund for the Doctoral Program of Higher Education (20120172110012), the Fundamental Research Funds for the Central Universities, and the Natural Science Foundation of Guangdong Province (S2011020002397 and 2013B090500027). 
the reaction mixture was difficult. Sun's group [14] prepared the same Ni@Pd NPs by a one-step method, and these NPs, supported on graphene, exhibited high catalytic activity during Suzuki-Miyaura cross-coupling reactions.

Functionalized anilines are important intermediates in the pharmaceutical, chemical, agrochemical, and dye industries [15]. The traditional non-catalytic reduction of nitroarenes using stoichiometric reducing reagents such as sodium borohydride, silanes, and hydrazine derivatives often causes serious environmental problems [16], and so catalytic hydrogenation with supported metal catalysts has captured widespread research interest in recent years $[17,18]$. Under mild reaction conditions, heterogeneous noble catalysts such as $\mathrm{Au} / \mathrm{TiO}_{2}$, $\mathrm{Au} / \gamma-\mathrm{Al}_{2} \mathrm{O}_{3}$, and Pd-Pt-carbon nanotubes (CNTs) have exhibited highly selective reduction of nitroarenes. However, the majority of these transformations were associated with relatively low turnover frequency (TOF) values that would need to be further improved to realize the practical applications of noble-metal catalysts [19-21].

In the present work, Ni@Pd core-shell NPs with different $\mathrm{Ni} / \mathrm{Pd}$ molar ratios were synthesized using a sequential reduction method. In this process, $\mathrm{Ni}$ and Pd precursors were sequentially reduced by oleylamine (OAm) and trioctylphosphine (TOP) to produce the desired NPs. Subsequently, these NPs were deposited on a MIL-101 metal-organic framework (MOF) using a simple impregnation method. The novel MIL-101 supported Ni@Pd NPs that resulted were found to be highly efficient in the reduction of nitroarenes under mild reaction conditions. $\mathrm{Cr}$ (III)-based MIL-101, a mesoporous MOF with the molecular formula $\mathrm{Cr}_{3} \mathrm{~F}\left(\mathrm{H}_{2} \mathrm{O}\right)_{2} \mathrm{O}\left[\left(\mathrm{O}_{2} \mathrm{C}\right) \mathrm{C}_{6} \mathrm{H}_{4}\left(\mathrm{CO}_{2}\right)\right]_{3} \cdot n \mathrm{H}_{2} \mathrm{O}(n=25)$ was chosen because it has a high surface area, good stability, and numerous potentially active $\mathrm{Cr}$ sites (up to $3.0 \mathrm{mmol} / \mathrm{g}$ ) upon removal of the terminal water molecules [22]. The Lewis acidity of MIL-101 has been demonstrated to play a significant role in promoting the reactivity of aromatic substrates [2,23]. In addition, we have previously shown that Pd NPs can be well dispersed on this MOF and subsequently show high activity and stability [24].

\section{Experimental}

\subsection{General}

All chemicals were obtained from commercial sources and were used without any further purification. Powder X-ray diffraction (XRD) patterns of MIL-101 samples were obtained using a Rigaku diffractometer (D/MAX-IIIA, $3 \mathrm{~kW}$ ) with $\mathrm{Cu} K_{\alpha}$ radiation $(40 \mathrm{kV}, 30 \mathrm{~mA}, \lambda=0.1543 \mathrm{~nm})$. Brunauer-EmmettTeller (BET) surface areas and pore volumes of the materials were assessed with a Micromeritics ASAP 2020 instrument based on $\mathrm{N}_{2}$ adsorption at $-196{ }^{\circ} \mathrm{C}$ after evacuation at $150{ }^{\circ} \mathrm{C}$ for $12 \mathrm{~h}$. The $\mathrm{Ni}$ and $\mathrm{Pd}$ contents of the samples were quantitatively determined by atomic absorption spectroscopy (AAS) with a HITACHI Z-2300 instrument. Fourier transform infrared (FT-IR) spectra of the samples were obtained on a Thermo Scientific Nicolet iS10 spectrometer with a Smart OMNI transmission accessory. Transmission electron microscopy (TEM) micrographs of the samples were acquired using a JEM-2010HR (JEOL).

\subsection{Synthesis of Ni@Pd NPs}

Palladium(II) bromide (PdBr2, $26.6 \mathrm{mg}, 0.1 \mathrm{mmol})$, nickel(II) acetate tetrahydrate $\left(\mathrm{Ni}(\mathrm{ac})_{2} \cdot 4 \mathrm{H}_{2} \mathrm{O}, 24.9 \mathrm{mg}, 0.1 \mathrm{mmol}\right)$, TOP $(0.5 \mathrm{~mL})$, and OAm $(10.0 \mathrm{~mL})$ were added to a $25 \mathrm{~mL}$ Teflon-lined, stainless steel autoclave contained in a glovebox filled with nitrogen at room temperature. This mixture was then heated at $255^{\circ} \mathrm{C}$ for $2 \mathrm{~h}$ and subsequently allowed to cool slowly to room temperature. The NP product was separated from the reaction mixture by adding $40 \mathrm{~mL}$ isopropanol, followed by two centrifugations at $10000 \mathrm{rpm}$ for $10 \mathrm{~min}$. The NPs were further purified and collected by first dispersing them in anhydrous $n$-hexane $(5 \mathrm{~mL})$ then adding a 1:1 mixture of ethanol and isopropanol and centrifuging at $10000 \mathrm{rpm}$ for $10 \mathrm{~min}$. The resulting NP powder was redispersed in anhydrous $n$-hexane. The prepared Ni@Pd core-shell NPs had a $\mathrm{Ni}$ :Pd molar ratio of approximately $1: 1$. Under the same conditions, the use of $0.1 \mathrm{mmol} \mathrm{PdBr}_{2}$ with 0.5 or $0.05 \mathrm{mmol}$ $\mathrm{Ni}(\mathrm{ac})_{2} \cdot 4 \mathrm{H}_{2} \mathrm{O}$ gave $\mathrm{Ni@Pd}$ core-shell NPs with Ni:Pd molar ratios of 5:1 and 0.5:1, respectively. Monometallic $\mathrm{Ni}$ and $\mathrm{Pd}$ NPs were synthesized using the same method.

\subsection{Synthesis of Ni@Pd/MIL-101 and other catalysts}

$\mathrm{Ni@Pd/MIL-101} \mathrm{catalysts} \mathrm{were} \mathrm{synthesized} \mathrm{using} \mathrm{an}$ impregnation method. Typically, $400 \mathrm{mg}$ of activated MIL-101 was dispersed in $10 \mathrm{~mL}$ of anhydrous $n$-hexane and stirred for $1 \mathrm{~h}$ at room temperature. The previously-prepared dispersion of NPs in $n$-hexane was then added dropwise to the above solution followed by stirring for $12 \mathrm{~h}$. Each impregnated MIL-101 sample was washed with anhydrous $n$-hexane until colorless filtrate was obtained and then slowly dried under vacuum at $150{ }^{\circ} \mathrm{C}$ for $12 \mathrm{~h}$ to obtain Ni@Pd/MIL-101. Samples of Ni/MIL-101, Pd/MIL-101, and Ni@Pd/AC were synthesized using the same method, while NiPd/MIL-101 and Ni@Pd/EnMIL-101 were synthesized following procedures previously reported in the literature [25]. The resulting Ni and Pd concentrations in the catalysts were determined by AAS.

\subsection{Nitroarenes reduction reaction}

The substrate (0.5 mmol), Ni@Pd/MIL-101 catalyst $(0.023$ $\mathrm{g}, \mathrm{Pd} 0.2 \mathrm{~mol} \%$ ), and ethyl acetate $(4 \mathrm{~mL})$ were added to a Schlenk tube, and the mixture was vigorously stirred with an affixed hydrogenation balloon at room temperature. Following the reaction, the solid catalyst was removed from the solution by filtration and washed with ethyl acetate. The product yields were determined by gas chromatography-mass spectrometry (GC/MS, Shimadzu GCMS-QP5050A) with a $0.25 \mathrm{~mm} \times 30 \mathrm{~m}$ DB-WAX capillary column. Parameters were as follows: initial oven temperature, $100{ }^{\circ} \mathrm{C}, 1 \mathrm{~min}$; ramp, $20{ }^{\circ} \mathrm{C} / \mathrm{min}$; final temperature, $280^{\circ} \mathrm{C}$; final time, $5 \mathrm{~min}$.

During recyclability trials, reactions were performed under the same conditions as above, except using recovered catalyst. 
Each time, the catalyst was separated from the reaction mixture at the end of the reaction, washed with ethyl acetate and then dried at $150{ }^{\circ} \mathrm{C}$ under vacuum prior to reuse.

\section{Results and discussion}

\subsection{Characterization results of the materials}

The XRD pattern of the as-synthesized MIL-101 is in good agreement with previously published XRD patterns (Fig. 1). There is no apparent loss of crystallinity and no identifiable peaks attributed to the metal NPs after impregnation, indicating that the MIL-101 framework maintained its structural integrity and that very small NPs were present on the MIL-101. Some minor changes in the relative peak intensities were observed in the case of the Ni@Pd/En-MIL-101, which could be related to grafting of ethane diamine onto the $\mathrm{Cr}$ sites of the framework.

The $\mathrm{N}_{2}$ adsorption isotherms of the samples were subsequently acquired at $-196{ }^{\circ} \mathrm{C}$, as shown in Fig. 2 , and the BET surface areas were calculated by choosing $\mathrm{N}_{2}$ adsorption points in the $p / p_{0}$ range of $0.05-0.3$. BET surface areas of 2912, 2790, $2685,2635,2449$, and $2324 \mathrm{~m}^{2} / \mathrm{g}$ were determined, along with pore volumes of $1.5,1.45,1.39,1.37,1.36$, and $1.33 \mathrm{~cm}^{3} / \mathrm{g}$, for the as-synthesized MIL-101, Ni/MIL-101, Pd/MIL-101, 0.15\%Ni@0.45\%Pd/MIL-101, 0.26\%Ni@0.46\%Pd/MIL-101, and 1.51\%Ni@0.46\%Pd/MIL-101 (where the numerical values indicate mass percentages), respectively. The slight decreases in $\mathrm{N}_{2}$ adsorption amounts and BET surface areas indicate that the core-shell NPs supported on the MIL-101 either occupied or blocked part of the pores or cavities of the MOF material.

Fig. 3 presents TEM images of the unsupported metal NPs and Ni@Pd/MIL-101 samples. As shown in Fig. 3(a)-(c), the average sizes of the unsupported NPs were all in the range of 8-9 $\mathrm{nm}$. This result indicates that the Ni:Pd ratio does not significantly affect the NP size. In addition, Fig. 3(d)-(e) demonstrates that the metal NPs were well dispersed on MIL-101.

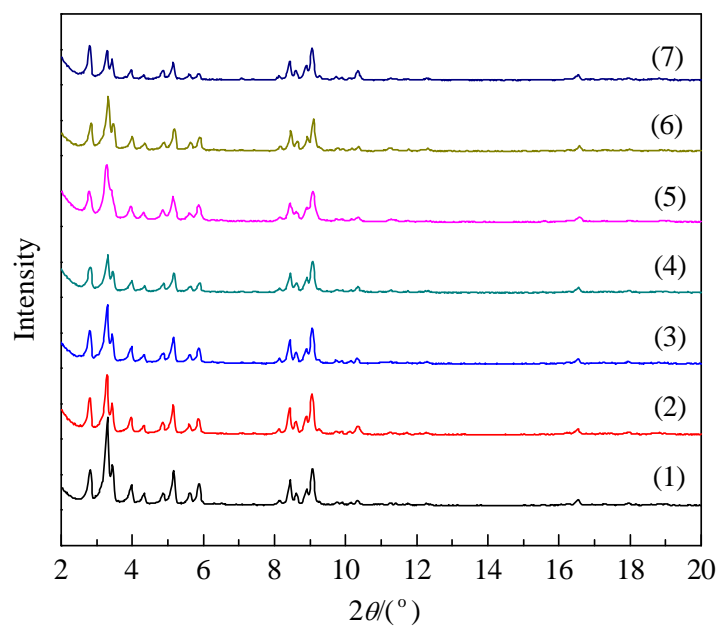

Fig. 1. Powder XRD patterns of (1) MIL-101 (as-synthesized), (2) $0.26 \% \mathrm{Ni} @ 0.46 \% \mathrm{Pd} / \mathrm{MIL}-101$, (3) $0.42 \% \mathrm{Pd} / \mathrm{MIL}-101$, (4) $0.26 \% \mathrm{Ni} /$ MIL-101, (5) 0.26\%Ni0.46\%Pd/MIL-101, (6) reused 0.26\% Ni@ 0.46\%Pd/MIL-101, and (7) 0.26\%Ni@0.46\%Pd/En-MIL-101.

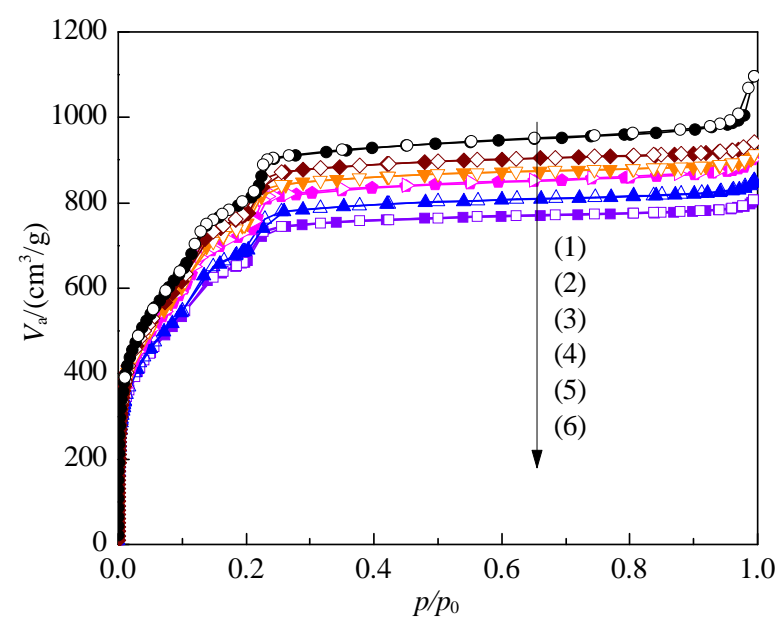

Fig. 2. $\mathrm{N}_{2}$ adsorption-desorption isotherms of various materials at -196 ${ }^{\circ}$. (1) MIL-101; (2) Ni/MIL-101; (3) Pd/MIL-101; (4) 0.15\%Ni@ 0.45\%Pd/MIL-101; (5) 0.26\%Ni@0.46\%Pd/MIL-101; (6) 1.51\%Ni@ $0.46 \% \mathrm{Pd} / \mathrm{MIL}-101$. Open symbols indicate desorption branches.

However, increasing the metal loading to approximately $2 \%$ (by mass) evidently generated metal NP aggregates (Fig. 3(f)). The core-shell NPs are also observed to have a polycrystalline structure. In agreement with the literature reports [14], the outer layer has a lattice fringe distance of $0.232 \mathrm{~nm}$ that may represent the (111) planes of face-centered cubic (fcc) Pd with a normative lattice spacing of approximately $0.223 \mathrm{~nm}$. The interlayer in the core has a lattice spacing of $0.214 \mathrm{~nm}$ and represents a variation of the crystal lattice parameters of $\mathrm{Ni}(111)$. In contrast, the standard lattice spacing of $\mathrm{Ni}(111)$ is on the order of $0.203 \mathrm{~nm}$ [26]. The observed differences between the $\mathrm{Pd}(111)$ and $\mathrm{Ni}(111)$ lattice spacing and the standard values can be attributed to the interaction between the $\mathrm{Ni}$ and $\mathrm{Pd}$ in the NPs. EDS analysis determined that the Ni@Pd/MIL-101 was composed of C, O, Cr, P, Ni, and Pd (Fig. 3(i)). The $\mathrm{Cu}$ signal in the EDS data arises from the sample holder, while the P signal comes from the TOP used in the samples preparation process.

The FT-IR spectra of $0.26 \% \mathrm{Ni@0.46 \% Pd/MIL-101} \mathrm{and}$ MIL-101 samples are shown in Fig. 4. The aliphatic C-H stretching vibrations (at 2800-3000 $\mathrm{cm}^{-1}$ ) observed for Ni@Pd/MIL-101 indicate the presence of TOP, possibly coordinated to a Lewis acid center [2,27]. This observation suggests the probable grafting of $\mathrm{P}$ groups onto the coordinately-unsaturated $\mathrm{Cr}$ sites in the MIL-101. In addition, the EDS results also show a $\mathrm{P}$ peak, confirming the presence of the phosphine ligand in the sample, whereas a $\mathrm{N}$ signal from the OAm is not present (Fig. 3(i)). The phosphine ligands may bridge between the NPs and the unsaturated $\mathrm{Cr}$ sites, allowing the NPs to be highly dispersed on the MIL-101.

\subsection{Nitroarenes reduction catalyzed by Ni@Pd/MIL-101}

The catalytic hydrogenation of nitrobenzene was performed at $30{ }^{\circ} \mathrm{C}$ under $\mathrm{H}_{2}$ at a pressure of $0.1 \mathrm{MPa}$, and the results are summarized in Table 1. The original MIL-101 was found to exhibit no activity in this catalytic reaction system (Table 1, 

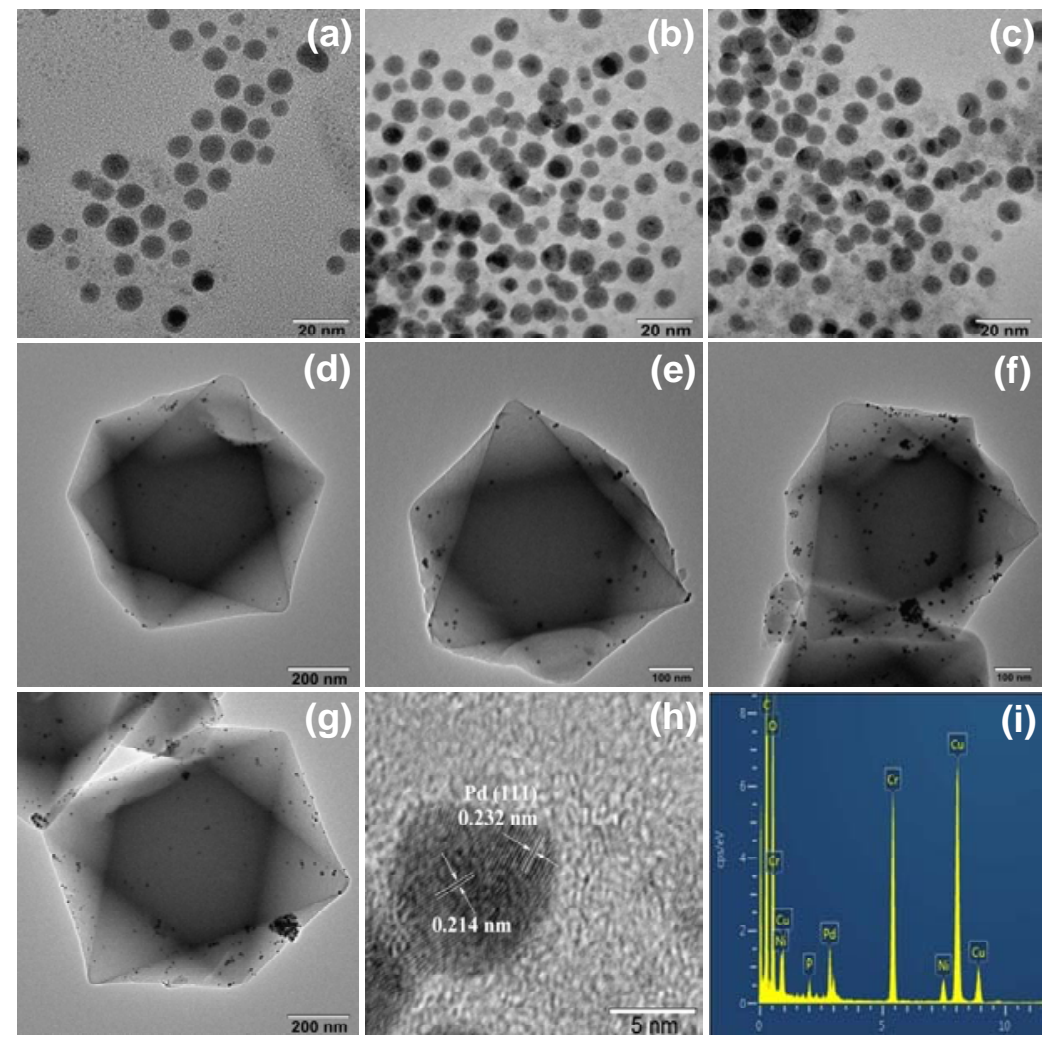

Fig. 3. TEM images of unsupported $\mathrm{Ni@Pd} \mathrm{NPs} \mathrm{having} \mathrm{Ni:Pd} \mathrm{molar} \mathrm{ratios} \mathrm{of} 0.5: 1$ (a), $1: 1$ (b), and 5:1 (c); TEM images of 0.15\%Ni@0.45\%Pd/MIL-101 (d), 0.26\%Ni@0.46\%Pd/MIL-101 (e), 1.51\%Ni@0.46\%Pd/MIL-101 (f), and 0.26\%Ni@0.46\%Pd/MIL-101 following reuse over five trials (g); HRTEM image of Ni@Pd NPs (with Ni:Pd molar ratio of 1:1) (h); Energy dispersive X-ray (EDS) spectrum of the as-synthesized 0.26\%Ni@0.46\%Pd/MIL-101 (i).

entry 1). In addition, the activity of the catalysts were highly dependent on the Ni-Pd compositions. Evidently, the core-shell Ni@Pd/MIL-101 samples were capable of higher activity (Table 1, entries 2-4). The results of the nitrobenzene reductions show that the best performance was obtained from the $0.26 \% \mathrm{Ni} @ 0.46 \% \mathrm{Pd} / \mathrm{MIL}-101$ (Table 1, entry 3), with 71\% conversion of nitrobenzene to aniline within $1 \mathrm{~h}$ at $30^{\circ} \mathrm{C}$. Using the $0.26 \% \mathrm{Ni} @ 0.46 \% \mathrm{Pd} / \mathrm{MIL}-101$ catalyst, a number of solvents were also screened, and this process indicated that ethylacetate is the best solvent for this transformation under the current conditions (Table 1, entry 5). In ethanol, the aniline product was observed to further react with the solvent to produce un-

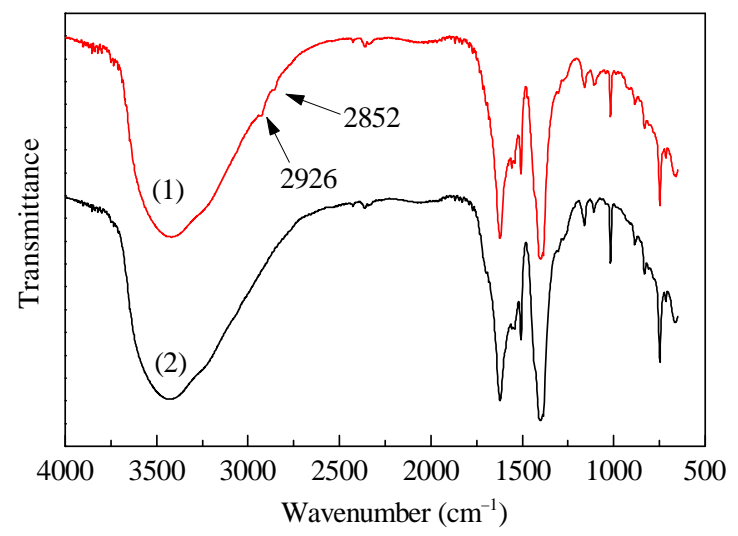

Fig. 4. Infrared spectra of (1) Ni@Pd/MIL-101 and (2) MIL-101. wanted side products such as $\mathrm{N}$-ethylaniline, leading to a lower yield. The optimized Ni@Pd/MIL-101 catalyst gave a TOF value of $375 \mathrm{~h}^{-1}$, a very high value under such mild conditions compared to results reported in the literature $[20,28,29]$.

The catalytic activity of the $0.26 \% \mathrm{Ni} @ 0.46 \% \mathrm{Pd} / \mathrm{MIL}-101$ was almost twice that of the monometallic Pd catalyst (Table 1 , entry 6), possibly because of the increased dispersion of Pd on

\section{Table 1}

Results from the hydrogenation of nitrobenzene with various catalysts.<smiles>C#CC(Cc1cccc(N)c1)C(=O)O[Na]</smiles>

\begin{tabular}{|c|c|c|c|c|}
\hline Entry & Catalyst & Solvent & $\begin{array}{c}\text { Yield }^{a} \\
(\%)\end{array}$ & $\begin{array}{l}\text { TOF } \\
\left(\mathrm{h}^{-1}\right)\end{array}$ \\
\hline 1 & MIL-101 & EtOH & 0 & 0 \\
\hline 2 & 1.51\%Ni@0.46\%Pd/MIL-101 & EtOH & 65 & 325 \\
\hline 3 & 0.26\%Ni@0.46\%Pd/MIL-101 & EtOH & 71 & 355 \\
\hline 4 & 0.15\%Ni@0.45\%Pd/MIL-101 & EtOH & 51 & 255 \\
\hline 5 & 0.26\%Ni@0.46\%Pd/MIL-101 & EtOAc & 75 & 375 \\
\hline 6 & $0.42 \% \mathrm{Pd} / \mathrm{MIL}-101$ & EtOAc & 39 & 195 \\
\hline $7 \mathrm{~b}$ & $0.26 \% \mathrm{Ni} / \mathrm{MIL}-101$ & EtOAc & 0 & 0 \\
\hline 8 & NiPd/MIL-101 & EtOAc & 41 & 205 \\
\hline 9 & 0.26\%Ni@0.46\%Pd/En-MIL-101 & EtOAc & 23 & 115 \\
\hline 10 & 0.26\%Ni@0.47\%Pd/AC & EtOAc & 3 & 15 \\
\hline
\end{tabular}

Reaction conditions: nitrobenzene $(0.5 \mathrm{mmol})$, catalyst $(0.023 \mathrm{~g}, \mathrm{Pd} 0.2$ mol\%), solvent $(4 \mathrm{~mL}), 30{ }^{\circ} \mathrm{C}, 1 \mathrm{~h}, \mathrm{H}_{2}(0.1 \mathrm{MPa})$. a Yields were determined by GC-MS analysis. ${ }^{\mathrm{b}}$ Catalyst $(0.023 \mathrm{~g}), 12 \mathrm{~h}$. 
the Ni core, generating a greater quantity of exposed Pd active sites, as well as the Ni-Pd interaction resulting from the core-shell structure. The catalytic activity of this material was also significantly higher than that of the bimetallic alloy NiPd/MIL-101 catalyst (Table 1, entry 8). Notably, Ni is not active in this reaction system even with a much longer reaction time (Table 1, entry 7).

For comparison purposes, the amine-grafted material

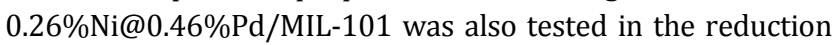
of nitrobenzene under the optimized reaction conditions. The use of this catalyst led to inferior activity in the reduction (Table 1 , entry 9 ), giving only a $23 \%$ yield of aniline. The remarkably reduced activity of Ni@Pd/MIL-101 upon amine grafting on the unsaturated chromium sites of MIL-101 suggests that the uncoordinated Lewis acidic $\mathrm{Cr}$ sites play an important role in the nitrobenzene reduction. This result correlates well with the

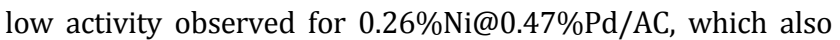
possesses low Lewis acidity (Table 1, entry 10). These findings also agree with observations that activated MIL-101 can promote the conversions of aromatics through the interaction between the uncoordinated Lewis acidic $\mathrm{Cr}$ sites and the aromatic rings $[22,30]$.

We attempted to extend this catalytic system to the reduction of a series of nitroarenes, using the optimized

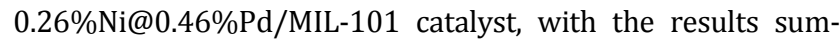
marized in Table 2. It can be seen that Ni@Pd/MIL-101 was highly active and selective for the reduction of most of the substrates, indicating the high versatility of the MOF-supported core-shell catalyst. Substituted nitroarenes containing electron-withdrawing or electro-donating functional groups all underwent excellent conversions with good selectivity to the corresponding anilines (Table 2, entries 1-6).

The chemoselective hydrogenation of nitroarenes having additional unsaturated substituents is a significant challenge. However, our Ni@Pd/MIL-101 catalyst was found to be highly active and chemoselective for the hydrogenation of various

Table 2

Hydrogenation of various substituted nitroarenes over the Ni@Pd/MIL-101 catalyst.

\begin{tabular}{|c|c|c|c|c|c|c|c|c|c|c|c|c|c|}
\hline Entry & Substrate & Product & $\begin{array}{c}\text { Time } \\
\text { (h) }\end{array}$ & $\begin{array}{l}\text { Con. } \\
(\%)\end{array}$ & $\begin{array}{l}\text { Sel. } \\
(\%)\end{array}$ & $\begin{array}{l}\text { TOF } \\
\left(\mathrm{h}^{-1}\right) \\
\end{array}$ & Entry & Substrate & Product & $\begin{array}{c}\text { Time } \\
(\mathrm{h})\end{array}$ & $\begin{array}{l}\text { Con. } \\
(\%)\end{array}$ & $\begin{array}{l}\text { Sel. } \\
\text { (\%) }\end{array}$ & $\begin{array}{l}\text { TOF } \\
\left(\mathrm{h}^{-1}\right)\end{array}$ \\
\hline 1 & & & 2 & 97 & 99 & 243 & 11 & & & 2.5 & 100 & 99 & 198 \\
\hline 2 & & & 2 & 100 & 99 & 248 & 12 & & & 1 & 100 & 99 & 495 \\
\hline 3 & & & 1 & 100 & 99 & 495 & 13 & & & 5 & 98 & 88 & 96 \\
\hline 4 & & & 1 & 100 & 99 & 495 & 14 & & & 1 & 100 & 99 & 495 \\
\hline 5 & & & 1 & 96 & 99 & 475 & 15 & & & 2 & 100 & 99 & 248 \\
\hline 6 & & & 1 & 95 & 99 & 470 & $16^{a}$ & & & 18 & 51 & 99 & 14 \\
\hline 7 & & & 1 & 100 & 99 & 495 & 17 a & & & 18 & 72 & 99 & 20 \\
\hline 8 & & & 1 & 95 & 99 & 470 & 18 & & & 18 & 100 & 92 & 26 \\
\hline 9 & & & 1 & 97 & 95 & 461 & 19 a & & & 18 & 100 & 73 & 20 \\
\hline 10 & & & 1 & 100 & 99 & 495 & & & & & & & \\
\hline
\end{tabular}

Reaction conditions: substrate ( $0.5 \mathrm{mmol}), 0.26 \% \mathrm{Ni} @ 0.46 \% \mathrm{Pd} / \mathrm{MIL}-101(0.023 \mathrm{~g}, \mathrm{Pd} 0.2 \mathrm{~mol} \%)$, ethyl acetate $(4 \mathrm{~mL}), 30^{\circ} \mathrm{C}, 1 \mathrm{bar} \mathrm{H}_{2}$.

${ }^{a}$ Solvent: ethyl acetate and dichloromethane mixture $(1: 1,4 \mathrm{~mL})$. 
substituted nitroarenes, with the exception of nitrostyrene (Table 2, entries 7-19). In addition, the ethenyl moiety is so active that both the nitro and ethenyl groups are simultaneously hydrogenated (Table 2 , entry 11). In most cases, the selectivity for the functionalized aniline was $>99 \%$, with a nitroarene conversion of $100 \%$. The exception was the hydrogenation of nitroarenes containing polyunsaturated substituents and unsaturated heterocyclic groups, for which lower activity were observed (Table 2, entries 16-19).

\subsection{Recycling of the Ni@Pd/MIL-101 catalyst}

The recyclability of the Ni@Pd/MIL-101 catalyst was examined during nitrobenzene reduction under the optimized conditions. The results presented in Fig. 5 indicate that only a small loss in conversion and selectivity resulted from the reduction of nitrobenzene over up to five replicate trials. After five reuses, the XRD pattern of the catalyst showed no appreciable change in the crystallinity of the MIL-101 material (Fig. 1). However, the Ni@Pd/MIL-101 catalyst did exhibit slight aggregation, which may have been responsible for the small decline in the catalytic performance (Fig. 3(g) and Fig. 5).

\section{Conclusions}

We have achieved the first-ever successful synthesis of $\mathrm{Ni}$-Pd core-shell NPs by a sequential reduction method followed by deposition on an MOF support. The as-prepared Ni@Pd/MIL-101 catalysts are highly active and selective during the hydrogenation of nitroarenes to anilines. Under mild reaction conditions $\left(30{ }^{\circ} \mathrm{C}, \mathrm{H}_{2}\right.$ pressure $\left.0.1 \mathrm{MPa}\right)$, the $\mathrm{Ni@Pd/MIL-101} \mathrm{gives} \mathrm{a} \mathrm{TOF} \mathrm{as} \mathrm{high} \mathrm{as} 375 \mathrm{~h}^{-1}$ for the hydrogenation of nitrobenzene and exhibits a broad substrate scope for substituted nitroarenes. The superior performance of the catalyst can be attributed to the strong Ni-Pd interaction in the core-shell structure, together with the role of the MIL-101 support in promoting the conversions of aromatics through uncoordinated Lewis acidic $\mathrm{Cr}$ sites. The strategy and approach disclosed here are general and could be extended to the design and development of other novel bimetal NP catalysts.

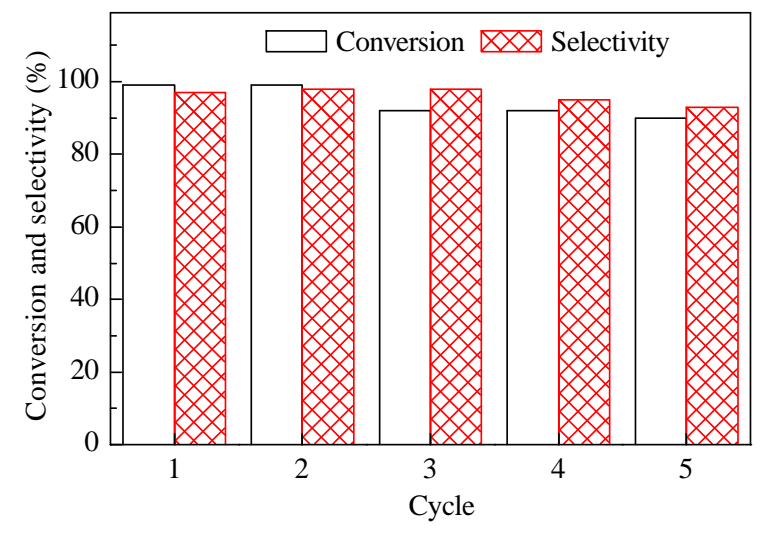

Fig. 5. Reuse of Ni@Pd/MIL-101.

\section{References}

[1] J. L. Pinilla, A. B. García, K. Philippot, P. Lara, E. J. García-Suárez, M. Millan, Fuel, 2014, 116, 729.

[2] G. Z. Chen, S. J. Wu, H. L. Liu, H. F. Jiang, Y. W. Li, Green Chem., 2013, $15,230$.

[3] B. Z. Yuan, Y. Y. Pan, Y. W. Li, B. L. Yin, H. F. Jiang, Angew. Chem. Int. Ed., 2010, 49, 4054.

[4] F. R. Wang, S. S. Tang, Y. H. Yu, L. F. Wang, B. L.Yin, X H. Li, Chin. J. Catal., 2014, 35, 1921.

[5] M. R. Nabid, Y. Bide, N. Ghalavand, M. Niknezhad, Appl. Organomet. Chem., 2014, 28, 389.

[6] R. Ghosh Chaudhuri, S. Paria, Chem. Rev., 2012, 112, 2373.

[7] Y. Z. Chen, Q. Xu, S. H. Yu, H. L. Jiang, Small, 2015, 11, 71.

[8] P. P. Zhang, Y. B. Hu, B. H. Li, Q. J. Zhang, C. Zhou, H. B. Yu, X. J. Zhang, L. Chen, B. Eichhorn, S. H. Zhou, ACS Catal., 2015, 5, 1335.

[9] Q. Sun, X. Q. Zhang, Y. Wang, A. H. Lu, Chin. J. Catal., 2015, 36, 683.

[10] J. Hermannsdörfer, M. Friedrich, N. Miyajima, R. Q. Albuquerque, S. Kümmel, R. Kempe, Angew. Chem. Int. Ed., 2012, 51, 11473.

[11] S. U. Son, Y. Jang, J. Park, H. B. Na, H. M. Park, H. J. Yun, J. Lee, T. Hyeon, J. Am. Chem. Soc., 2004, 126, 5026.

[12] R. Massard, D. Uzio, C. Thomazeau, C. Pichon, J. L. Rousset, J. C.. Bertolini, J. Catal., 2007, 245, 133.

[13] M. M. Zhang, Z. X. Yan, Q. Sun, J. M. Xie, J. J. Jing, New J. Chem., 2012, 36, 2533.

[14] O. Metin, S. F. Ho, C. Alp, H. Can, M. N. Mankin, M. S. Gültekin, M. F. Chi, S. H. Sun, Nano Res., 2013, 6, 10.

\section{Graphical Abstract}

Chin. J. Catal., 2016, 37: 91-97 doi: 10.1016/S1872-2067(15)60940-8

\section{$\mathrm{Ni@Pd} \mathrm{core-shell} \mathrm{nanoparticles} \mathrm{supported} \mathrm{on} \mathrm{a} \mathrm{metal-organic}$ framework as highly efficient catalysts for nitroarenes reduction}

Siping Jian, Yingwei Li*

South China University of Technology

Bimetal core-shell Ni@Pd nanoparticles supported on MIL-101 were prepared and exhibit high catalytic activity and selectivity during the reduction of nitroarenes.

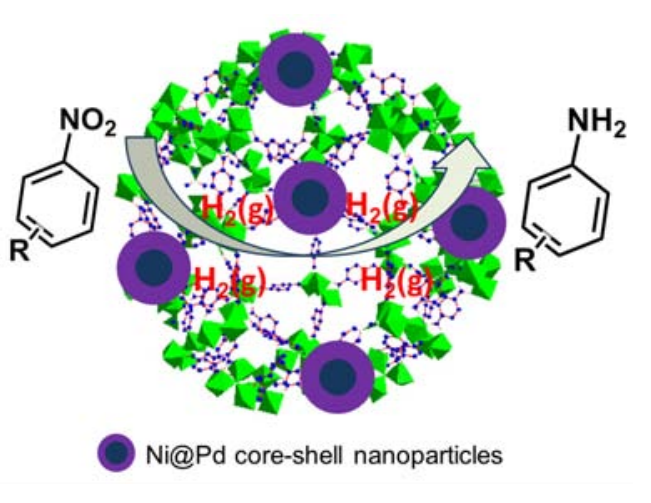


[15] H. S. Wei, X. Y. Liu, A. Q. Wang, L. L. Zhang, B. T. Qiao, X. F. Yang, Y. Q. Huang, S. Miao, J. Y. Liu, T. Zhang, Nat. Commun., 2014, 5, 5634.

[16] K. I. Shimizu, Y. Miyamoto, T. Kawasaki, T. Tanji, Y. Tai, A. Satsuma, J. Phys. Chem. C, 2009, 113, 17803.

[17] W. W. Lin, H. Y. Cheng, J. Ming, Y. C. Yu, F. Y. Zhao, J. Catal., 2012, $291,149$.

[18] W. C. Du, G. Z. Chen, R. F. Nie, Y. W. Li, Z. Y. Hou, Catal. Commun., 2013, 41, 56.

[19] K. Fuku, T. Sakano, T. Kamegawa, K. Mori, H. Yamashita, J. Mater. Chem., 2012, 22, 16243.

[20] E. Kim, H. S. Jeong, B. M. Kim, Catal. Commun., 2014, 45, 25.

[21] J. R. Niu, X. Huo, F. W. Zhang, H. B. Wang, P. Zhao, W. Q. Hu, J. T. Ma, R. Li, ChemCatChem, 2013, 5, 349.

[22] G. Férey, C. Mellot-Draznieks, C. Serre, F. Millange, J. Dutour, S. Surblé, I. Margiolaki, Science, 2005, 309, 2040.
[23] H. L. Liu, Y. W. Li, H. F. Jiang, C. Vargas, R. Luque, Chem. Commun., 2012, 48, 8431.

[24] Y. Y. Pan, B. Z. Yuan, Y. W. Li, D. H. He, Chem. Commun., 2010, 46, 2280.

[25] Y. K. Hwang, D. Y. Hong, J. S. Chang, S. H. Jhung, Y. K. Seo, J. Kim, A. Vimont, M. Daturi, C. Serre, G. Férey, Angew. Chem. Int. Ed., 2008, $47,4144$.

[26] M. M. Zhang, Z. X. Yan, J. M. Xie, Electrochim. Acta, 2012, 77, 237.

[27] Y. Pan, H. Y. Bai, L. Pan, Y. D. Li, M. C. Tamargo, M. Sohel, J. R.. Lombardi, J. Mater. Chem., 2012, 22, 23593.

[28] Y. Wu, D. S. Wang, Z. Q. Niu, P. C. Chen, G. Zhou, Y. D. Li, Angew. Chem. Int. Ed., 2012, 51, 12524.

[29] P. Wang, F. W. Zhang, Y. Long, M. Xie, R. Li, J. T. Ma, Catal. Sci. Technol., 2013, 3, 1618.

[30] Z. K. Zhao, H. L. Yang, Y. Li, RSC Adv., 2014, 4, 22669.

\title{
MIL-101负载Ni@Pd核壳纳米粒子催化芳香硝基类化合物加氢
}

\author{
简思平，李映伟 ${ }^{*}$ \\ 华南理工大学化学与化工学院, 制浆造纸工程国家重点实验室, 广东广州510640
}

摘要: 金属有机骨架 $(\mathrm{MOFs})$ 材料是一种新型的沸石类多孔材料, 是由金属离子和有机配体通过配位键键合而成的拓扑结 构. 相比其他多孔材料, MOFs拥有更高的比表面积、孔隙率以及结构可调控性. 在催化方面, MOFs复合材料在多相催化领 域已经引起了广泛的研究兴趣. 贵金属纳米颗粒是一种在化学、化工、生物和医学等许多领域有着广泛应用的高性能材 料. 但是, 催化反应往往都是发生在纳米颗粒的表面, 而位于颗粒内部的金属没能得到利用; 从原子经济性的角度来看, 以 廉价金属作核、贵金属作壳的双金属纳米粒子能有效解决这个问题, 而且还能利用双金属之间的协调作用. 目前文献中也 已经报道了多种非贵金属和贵金属组成的核壳双金属纳米粒子, 都展现出了比单纯贵金属更好的催化活性.

芳香胺类化合物是一种在工业上非常重要的有机中间体, 广泛应用于农药、药物、染料和色素等等. 目前, 商业化生产 的芳香胺化合物都是通过计量的还原剂, 如连二硫酸钠、硼氢化钠、水合肼和氨水中的铁、锡、锌等非催化还原相应的芳 硝基化合物得到, 这样往往会带来严重的环境污染问题. 而通过多相催化加氢还原方法来制备芳香胺化合物, 不仅能高效 催化芳硝基化合物加氢, 而且催化剂可以回收利用, 大大降低反应对环境的污染.

本文综合贵金属原子经济观点和芳硝基类化合物加氢反应催化剂设计,在油胺和三正辛基膦中通过热还原二价的镍 和钯, 制备出以 $\mathrm{Ni}$ 为核 $\mathrm{Pd}$ 为壳的双金属纳米粒子. 通过透射电镜观察, 镍钯核壳纳米粒子的粒径约为 $8-9 \mathrm{~nm}$. 选用具有高 比表面积和高稳定性的金属有机骨架材料MIL-101作为载体, 通过浸渍法首次将镍钯核壳纳米粒子负载在MIL-101上制备 出不同Ni:Pd比的Ni@Pd/MIL-101复合材料. 利用X射线粉末衍射(XRD)、 $\mathrm{N}_{2}$ 吸附-脱附、红外光谱、透射电子显微镜和X 射线能谱对复合材料结构进行了表征. 从XRD谱图能看出负载纳米粒子后的MIL-101材料结构依然保持完整, 表明催化剂 制备过程不会破坏载体结构. 红外光谱测试结果表明, 负载了镍钯纳米粒子的Ni@Pd/MIL-101复合材料中含有两种C-H键 伸缩振动 2852 和 $2926 \mathrm{~cm}^{-1}$ 处两个特征峰, 分别对应于 $-\mathrm{CH}_{2}-$ 和 $-\mathrm{CH}_{3}$ 中 $\mathrm{C}-\mathrm{H}$ 键的特征吸收峰, 可能是残留的油胺, 也可能是 三正辛基膦在与镍和钯形成配合物时的残留. $\mathrm{X}$ 射线能谱测试发现, $\mathrm{N}$ 元素在负载后已不存在, 而 $\mathrm{P}$ 元素依旧存在, 结合红 外光谱可以确认, 纳米粒子在负载前后三正辛基膦依然与纳米粒子稳定络合, 进而可被MIL-101上未饱和的Cr固定. 通过 透射电镜可以观察到镍钯核壳纳米粒子高度分散在载体上.

将Ni@Pd/MIL-101材料应用于硝基苯催化加氢反应. 在 $30^{\circ} \mathrm{C}, 0.1 \mathrm{MPa} \mathrm{H}_{2}$ 条件下, 0.26\%Ni@0.46\%Pd/MIL-101催化剂 具有最高的加氢活性, 其转换频率(TOF)值最高可达 $375 \mathrm{~h}^{-1}$, 是单金属负载钯催化剂的近 2 倍, 展示出非贵金属替代部分贵 金属的可行性. 在循环使用方面, 重复使用5次后的Ni@Pd/MIL-101催化剂依然保持较高的催化活性和选择性. 同时考察 了底物的兼容性, 该催化体系对多种不同基团(包括不饱和基团)取代的硝基苯化合物的催化加氢, 大都表现出很高的催化 活性和选择性, TOF值最高可达 $495 \mathrm{~h}^{-1}$.

关键词: 镍; 钯; 核壳纳米粒子; 金属有机骨架; 芳香硝基类化合物; 加氢; 多相催化

收稿日期: 2015-06-07. 接受日期: 2015-06-19. 出版日期: 2016-01-05.

*通讯联系人. 电话: (020)87113656; 电子信箱: liyw@scut.edu.cn

基金来源：国家自然科学基金(21322606, 21436005); 高等学校博士学科点专项科研基金(20120172110012); 华南理工大学中央 高校基本科研业务费专项资金; 广东省自然科学基金(S2011020002397, 2013B090500027).

本文的英文电子版由Elsevier出版社在ScienceDirect上出版(http://www.sciencedirect.com/science/journal/18722067). 